\title{
sciendo
}

CIVIL AND ENVIRONMENTAL ENGINEERING REPORTS

E-ISSN 2450-8594

CEER 2021; 31 (1): 0029-0043

DOI: $10.2478 /$ ceer-2021-0002

Original Research Article

\section{NUMERICAL STUDY OF THE BEHAVIOUR OF A CIRCULAR FOOTING ON A LAYERED GRANULAR SOIL UNDER VERTICAL AND INCLINED LOADING}

\author{
Surya Pratap SINGH*1, Amrit Kumar ROY ${ }^{2}$ \\ ${ }^{1}$ Student, Department of Civil Engineering, NIT Hamirpur, Himachal Pradesh, India \\ ${ }^{2}$ Department of Civil Engineering, NIT Hamirpur, Himachal Pradesh, India
}

\begin{abstract}
This paper aims to study the behaviour of a circular footing resting on two granular layers, i.e., a dense sand layer resting on loose sand strata, subjected to a vertical and an inclined loading $\left(\alpha=0^{\circ}, 10^{\circ}, 20^{\circ}, 30^{\circ}\right)$ using the finite element (FE) software PLAXIS-3D. The Mohr-Coulomb criterion is employed for the analysis of the model, in which two parameters are considered to vary significantly; (1) thickness of the top layer (dense layer) and (2) friction angle $(\phi)$ of both the layers. In the circular footing, the bearing capacity on the layered soil profile is assessed using the mechanism of punching shear failure following the desired area approach. The punching shear failure mechanism formed in dense sand has a parabolic shape at the ultimate load when the maximum mobilization of shear force through the failure surface is taken into account, otherwise, the punching failure is the actual failure while punching in the lower layer continues to a greater extent, depending on the interface load. Bearing pressure decreases as the inclination increases with respect to the vertical, along with bearing pressure increasing as the thickness of the dense sand layer increases. The software results compare well with data available from the literature.
\end{abstract}

Keywords: layered granular soil, numerical modelling, circular footing, model tests, inclined loading

\footnotetext{
* Corresponding author: Department of Civil Engineering, NIT Hamirpur, Himachal Pradesh, India, e-mail: pratapsurya140291@gmail.com
} 


\section{INTRODUCTION}

The behaviour of footings in layered soils is complex, and for many years has been a topic of concern. Various researchers have studied the behaviour of footings in homogeneous soft soils, and several design methods were developed to determine the ultimate carrying load. Using the limit equilibrium method, (Meyerhof, 1974) simplified expressions for finding the ultimate bearing capacity of the strip and circular footings with a sand layer overlying the clayey strata are suggested. In the sand layer, a punching shear failure mechanism was assumed, and a truncated pyramid, which moves the sand mass along with the base, was forced into it.

The action of foundations on layered soil has been studied in various ways: for example, regarding combinations of different types of soil such as sand (or clay) overlaying clay (or sand) (Meyerhof, 1974). Some of these studies are concerned with the objective of determining the bearing capacity when a dense sand layer is placed over soft clay. (Michalowski \& Shi, 1995)(Burd \& Frydman, 1997)(Shiau et al., 2003)(Chakraborty \& Kumar, 2015). Studies involving foundations on two layers of sand are rather limited (HANNA, 1981)(HANNA, 1982).

From the above, the ultimate bearing capacity of strips and circular foundations are calculated under an inclined load involving different layers of soil; (1) a dense sand layer over soft clay, (2) a dense sand layer over loose sand, (3) a stiff clay layer over a soft clay layer, and (4) a loose sand layer over a dense sand layer.

After a decade, (HANNA, 1982) gave the design charts for calculating the bearing capacities of strip and circular footings placed on (1) a dense sand layer overlying loose sand deposits and (2) a loose sand layer over dense sand media.

It is noted that the above studies were mainly concerned with the ultimate bearing capacity of layered foundations of different configurations, while very few mentioned their variation relative to the settlement of the footing in the determination of the bearing pressure design (Thakur \& Dutta, 2020). They are mainly carried out in a small-scale model in the laboratory or by the traditional conventional method in which the assumption was made in a simple manner. Most of the existing approaches for assessing the strip and circular footing problem over a two-layer soil mass are generally based on the simplifying assumption of the failure mechanism.

In comparison to the above, the aim of the present research is to conduct the model test in the finite element (FE) software PLAXIS-3D.

Two layers of soil model were designed in the FEM software Plaxis-3D. The top layer has dense granular soil having a depth $\mathrm{H}$ and the bottom layer has loose granular soil having a depth $\mathrm{H}^{\prime}$ in the model. $\mathrm{D}$ is the diameter of the circular footing. The depth $\mathrm{H}$ depends on the ratio $\mathrm{H} / \mathrm{D}$ which varies from 0.5 to 2.0. The total depth of the two layers is kept at 15D. Therefore, the depth of the bottom layer is $\mathrm{H}^{\prime}=15 \mathrm{D}-\mathrm{H}$. The circular footing is placed at the centre of the model and loading is applied at the centre of the footing (vertical as well as inclined loading). 
To remove the boundary effect due to loading, the horizontal dimensions are kept at 5D (either side of the footing)(Ornek et al., 2012) Fig. 1.

The effects of the thickness of the sand layer and its internal friction angle on the results were examined. Failure patterns have also been drawn up for a number of different cases. The results from the analysis were compared with the available theoretical and experimental data from the literature.

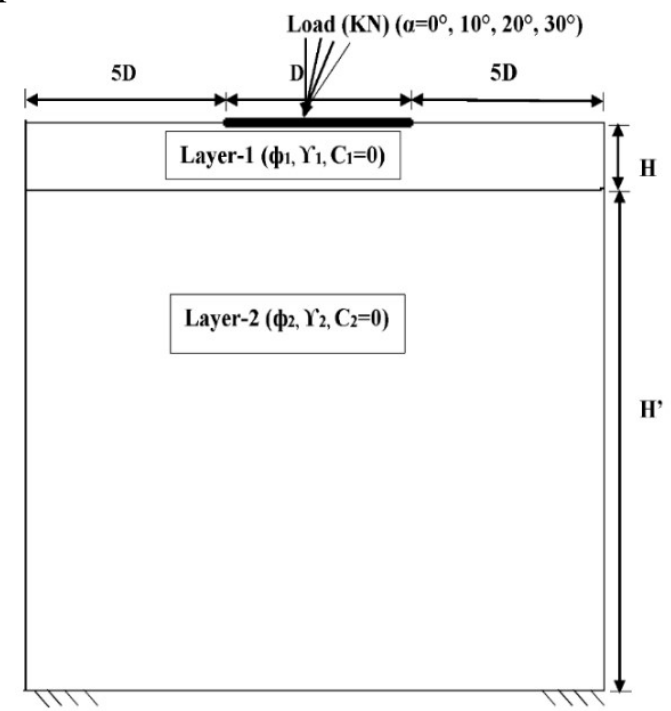

Fig. 1. Circular footing resting on a layered soil

\section{NUMERICAL MODEL}

Numerical analysis is a strong mathematical method making it possible to solve complex technical problems. The finite-element approach is a well-established numerical analysis methodology commonly used in many civil engineering applications, both for testing and for the design of practical engineering problems. The constitutive behaviour of soils can be modelled successfully in the numerical analysis. The finite element approach is one of the mathematical methods in which the soil model is divided into finite elements of various geometries. This gives the benefit of idealizing the material behaviour of the soil, which is non-linear with plastic deformations and is dependent on the direction of stress.

In this study, the numerical models were made using Finite Element (FE) software Plaxis-3D, a finite-element kit built specifically for studying deformation and stability in geotechnical engineering problems such that the stresses, strains, and failure conditions can be determined for a given issue.

Plaxis incorporates a fully automatic mesh generation procedure in which the geometry is divided into elements of two types; basic and compatible. 
There are five different mesh densities available in Plaxis, ranging from very coarse to very fine. Thus, to select the most suitable mesh for the present study, all five types of mesh were applied to the model as a preliminary computation whereby, in the very fine mesh, the number of elements was 15,740 while in the very coarse mesh it was 8,570 elements. From the above preliminary results, in a very coarse mesh the important features of the domain are untouched, and in a very fine mesh, the data obtained are inaccurate. Moreover, the time required in the simulation is very high per (Acharyya \& Dey, 2017). Also, the mesh converges reports that increasing the number of elements beyond 12,530 to 15740 has a negligible effect on the data obtained and as previously stated, the time required in the simulation is also very high.

In this study, the optimum mesh structure is used from coarse to fine mesh, i.e., $\left(9,500\right.$ to 11,900 elements) near the footing, and average element size is $5.33 \times 10^{-}$ ${ }^{3} \mathrm{~m}$ or less, corresponding to the different H/D ratio as shown in Fig. 2.

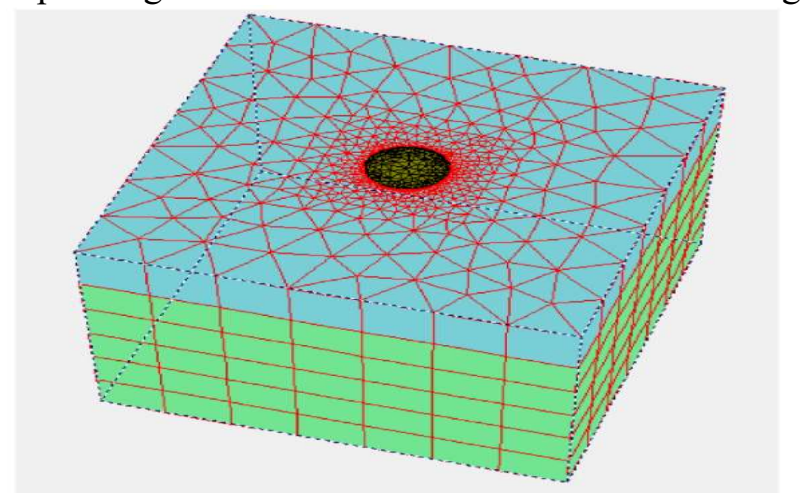

Fig. 2. Footing, soil bed, and meshing used in the analysis

In respect of boundary conditions, Plaxis automatically imposes several general fixes in the boundary of the geometry and smooth conditions at the vertical sides. The boundary conditions of the models were simulated such that the bottom boundary is fixed while the ground surface is free in all directions. In the numerical analysis, the dimensions of the model were generated based on the footing size (' $\mathrm{D}$ ' diameter of the footing). To remove the boundary effect due to loading, the horizontal and vertical dimensions are kept at 5D (either side of the footing) and 15D $\left(\mathrm{H}+\mathrm{H}^{\prime}\right)$. The soil medium was modelled using wedged 15-node elements. Typical graded finite-element mesh composed of soil and foundation, along with boundary conditions and geometry of the soil system, were as shown in Fig. 2. 


\subsection{Soil Layer}

A Mohr-Coulomb (MC) model is selected for this numerical study, which constitutes a two-layer granular soil, i.e., a top layer of dense granular soil and a bottom layer of loose granular soil. The MC model is selected in general practice because this model is applicable and includes only important properties of the soil that have existence in soil. In this, the failure state of stress is well described in the $\mathrm{MC}$ criterion of failure considering the effective parameters of the soil. The MC model includes five parameters, being unit weight $\Upsilon_{n}$, loading stiffness $E_{\mathrm{u}}$, friction angle $\phi^{\circ}$, dilation angle $\psi^{\circ}$, and Poisson's ratio $v$.

Table 1. Soil properties of layer-I and layer-II as per (Bowles, 1977)(Khatri et al., 2017)

\begin{tabular}{|c|c|c|}
\hline Parameters & Layer II (Loose Sand) & Layer I(Dense Sand) \\
\hline Unit weight, $y_{a}\left(\mathrm{NNm}^{3}\right)$ & $14 \cdot 16.5$ & $19-21.5$ \\
\hline Loxding stiffiness, $E_{k}\left(M P_{2}\right)$ & 22.8.38.4 & $68.4-102$ \\
\hline Poisson's ratio, $y$ & 0.2 & 0.3 \\
\hline Friction angle, $\phi^{\circ}$ & $31^{\circ} \cdot 35^{\circ}$ & $41^{\circ}-45^{\circ}$ \\
\hline $\begin{array}{l}\text { Distancy angle, } \Psi^{\circ} \\
\left(0.30^{\circ}\right)\end{array}$ & $1^{0} \cdot 5^{\circ}$ & $11^{\circ} \cdot 15^{\circ}$ \\
\hline Condition & Drained & Drained \\
\hline
\end{tabular}

The table represents the soil properties of the dense and loose soil layers. Unit weight, loading stiffness, and unit weight are as per (Bowles, 1977) (Khatri et al., 2017). The dilation angle is based on the equation given by the (Bolton, 1986), i.e., $\psi=\phi-30^{\circ}$.

\subsection{Load application and definition of load inclination}

To study the effect of loading on the behaviour of the circular footing over the layered soil, a point load is applied to the centre of the footing as shown in Fig. 3. Two types of point load are applied over the circular footing, a vertical as well as an inclined loading. The load is directly applied to the centre of the footing in the vertical loading, while the inclined loading is inclined relative to the vertical loading plane which is denoted as ' $\alpha$ '. For this study, three values of ' $\alpha$ ' were considered, i.e., $\alpha=10^{\circ}, 20^{\circ}$, and $30^{\circ}$. The value of ' $\alpha$ ' for vertical loading is $0^{\circ}$ (Sharma \& Kumar, 2018). 

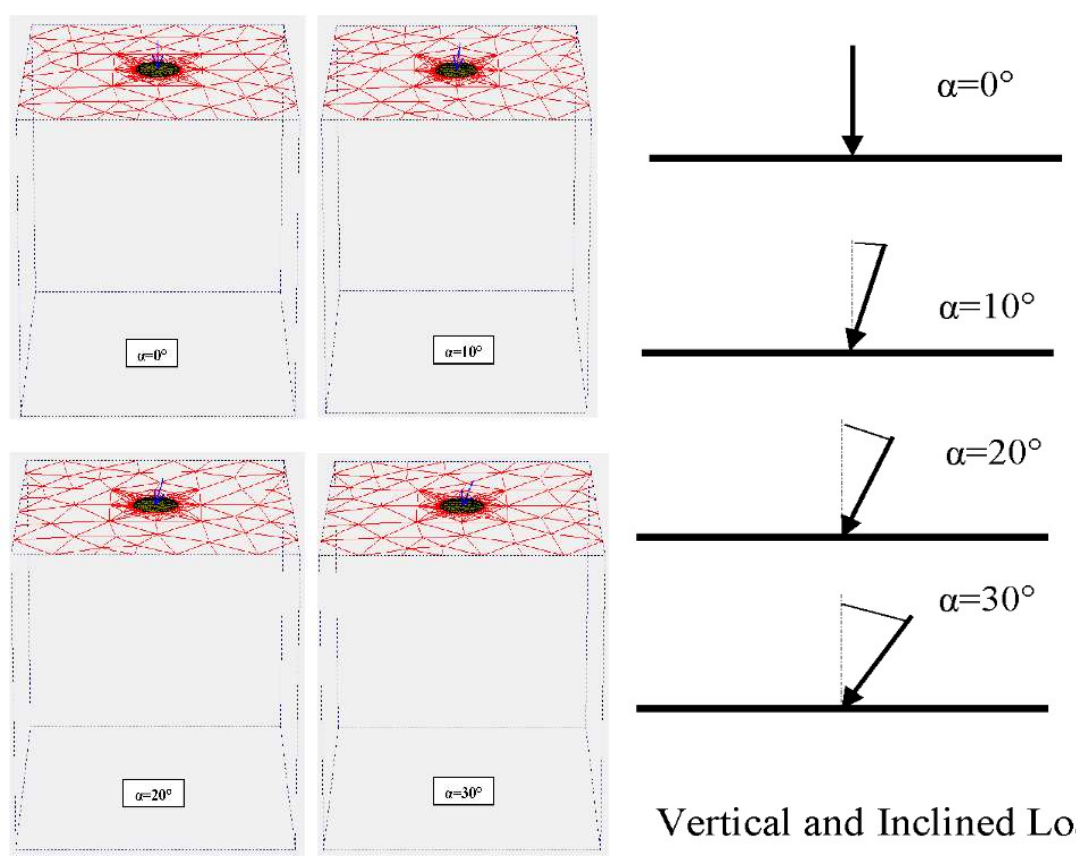

Vertical and Inclined Loading

Fig. 3. Vertical and inclined loading in geometric view and Plaxis-3D model view used in the analysis

\subsection{Footing}

To model the circular footing in FEM software, 15-noded wedge elements were used, acting as an elastic material. The footing is modelled as a concrete material with unit weight $\Upsilon=25 \mathrm{kPa}$ and young's modulus $\mathrm{E}=2 \times 10^{7} \mathrm{kPa}$. The diameter of the circular footing and thickness is kept constant throughout the computational study, i.e., $2 \mathrm{~m}$ and $0.05 \mathrm{~m}$ (Zidan, 2012).

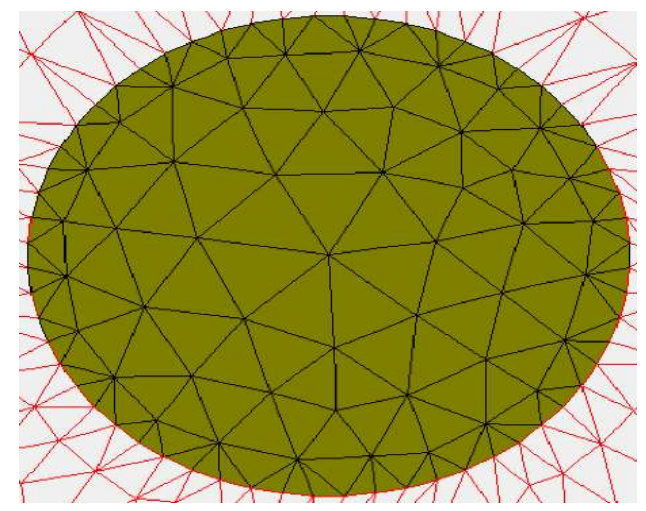

Fig. 4. Circular footing used in the analysis 


\section{VERIFICATION AND VALIDATION}

To verify the FEM software Plaxis-3D experimental research, the paper has opted. (Ornek et al., 2012) analysed a series of laboratory model tests performed on a circular footing. As shown in Fig. 5, the circular footing is at the surface of the granular soil layer which is resting over the natural clay. The loading frame is concentric to the centre of the footing and load is applied with the help of a hydraulic jack, Fig. 5 (a).

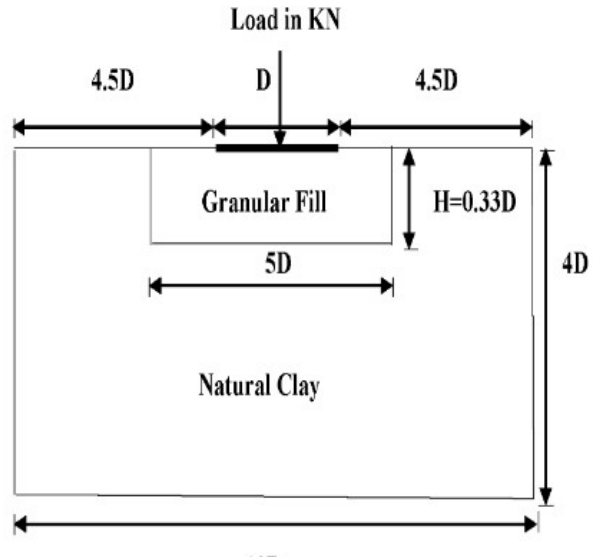

10D

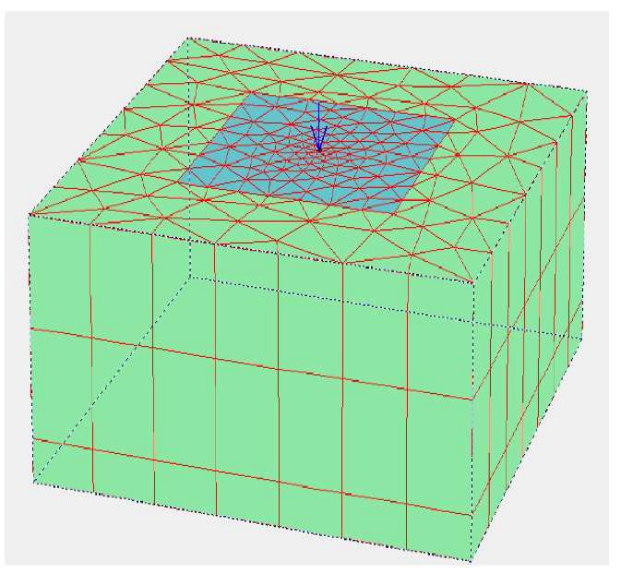

(b)

Fig. 5. (a) Geometric view of the experimental setup. (b) Plaxis-3D view of the experimental setup

The overall dimension of the tank is in terms of the diameter of the circular footing. The diameter of the circular footing is $0.12 \mathrm{~m}$ and the thickness of the footing is $0.02 \mathrm{~m}$. The total depth of the tank is $4 \mathrm{D}$ and the width is $10 \mathrm{D}$. The granular soil is filled beneath the footing having width 5D and depth $\mathrm{H}(\mathrm{H}=0.33 \mathrm{D})$ and the remaining tank is filled with natural clay as shown in Fig. 5. 
Table 2. Soil properties used in the experiment

\begin{tabular}{|c|c|c|}
\hline Parameters & Clay Layer & Granular Layer \\
\hline Unit weight, $\gamma_{2}\left(\mathrm{KN} / \mathrm{m}^{3}\right)$ & 18 & 21 \\
\hline Loading stiffness, $\mathrm{E}_{v}(\mathrm{MPa})$ & 8500 & 42500 \\
\hline Poisson's ratio, $v$ & 0.35 & 0.2 \\
\hline Friction angle, $\phi^{\circ}$ & $0^{\circ}$ & $43^{\circ}$ \\
\hline Dilatancy angle, $\Psi^{0}$ & $0^{\circ}$ & $13^{\circ}$ \\
\hline Colhesion, $c\left(\mathrm{KN} / \mathrm{mi}^{2}\right)$ & 75 & 0 \\
\hline
\end{tabular}

The Mohr-coulomb (MC) model is used for modelling the above experimental setup as per the given soil properties. Results are shown in Fig. 6. The experimental and FEM test results are compared in the graph, the FEM test result value is $525 \mathrm{kPa}$ and the experimental test result value is $485 \mathrm{kPa}$, which is slightly lower than the FEM test of approximately $8 \%$. The optimum meshing structure is applied in the FEM test which gives better and accurate results. Fine mesh is applied near the footing which gradually changes to a coarse mesh towards the edge of the model. The shading view test result shows the vertical displacement of the soil when a load is applied over the footing, Fig. 6.

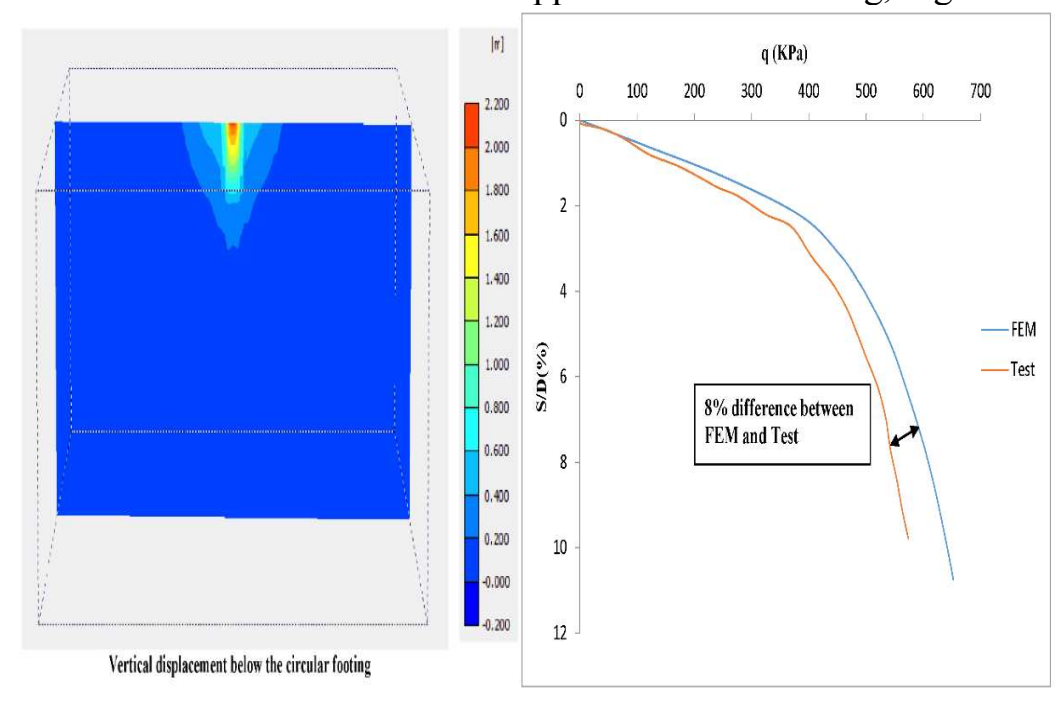

(a)

(b)

Fig. 6. (a) Shading view result in Plaxis-3D. (b) Comparison of the results from the experiment and FEM test 


\section{RESULTS AND DISCUSSION}

Finite element analysis was performed to study the effect of vertical and inclined loading on a circular footing placed in a two-granular soil (Layer-I dense sand and Layer-II loose sand), and the change in the H/D ratio of layer-I, i.e., 0.5-2.0, varying the value of friction angle of both layers.

\subsection{Two Layered Granular Soil Subjected to Inclined and Vertical Loading}

To perform the analysis of the two-layer sand media, the friction angle of the upper layer (dense sand), $\phi_{1}$ varied from $41^{\circ}-45^{\circ}$. On the other hand, the friction angle of the lower layer (loose sand), $\phi_{2}$ varied from $31^{\circ}-35^{\circ}$. The H/D ratio varied from 0.5-2.0; the parameter $\mathrm{H}$ defined the thickness of the upper layer and $\mathrm{D}$ defined the circular footing diameter.

Fig. 7 demonstrates both the pressure and the H/D ratio, which is plotted to show the variation in the graph when the loading inclination is changed from $\alpha=0^{\circ}$ to $30^{\circ}$ with respect to the vertical. The loading inclination is in the interval of $10^{\circ}$ as shown in Fig. 7 It shows the variation in bearing pressure concerning the loading along with the H/D ratio variation in the upper layer (dense sand) of the soil. Fig. 7 (a) has $\phi_{1}=41^{\circ}$ (friction angle for the upper layer) and $\phi_{2}=31^{\circ}$ (friction angle for the lower layer), $\mathrm{H} / \mathrm{D}=0.5$ which has bearing pressure of $290 \mathrm{kPa}$ for $\alpha=0^{\circ}$, $258 \mathrm{kPa}$ for $\alpha=10^{\circ}, 190 \mathrm{kPa}$ for $\alpha=20^{\circ}, 153 \mathrm{kPa}$ for $\alpha=30^{\circ}$ from Table 3. Bearing pressure decreases from $\alpha=0^{\circ}-30^{\circ}$ and this trend is observed and followed in each combination of the friction angle of the upper layer $\left(\phi_{1}\right)$ and lower layer $\left(\phi_{2}\right)$.

Another trend is also observed in Fig. 7; there is a sudden increase in the bearing pressure as the H/D ratio increases from 0.25 to 0.5 , then there is a gradual increase in the bearing pressure from 0.5 to 1.75 , again the same as above, a sudden increase in the bearing pressure when the H/D ratio increases from 1.75 to 2.0. For further observation, the H/D ratio is increased beyond 2.0, but there is only slightly significant change in the bearing pressure. 


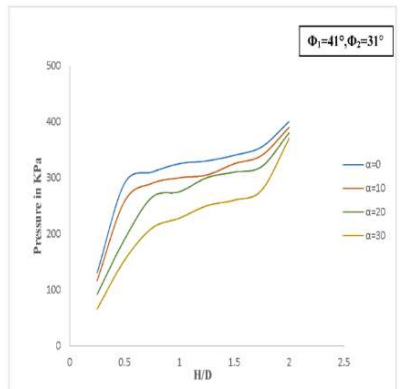

(a)

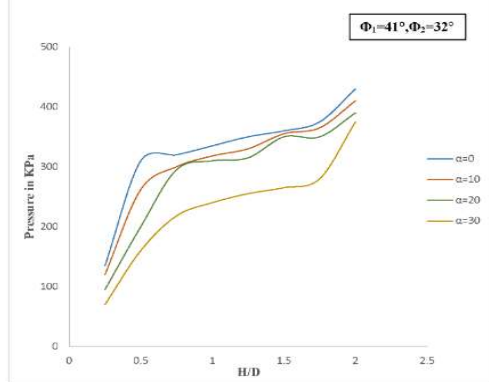

(c)

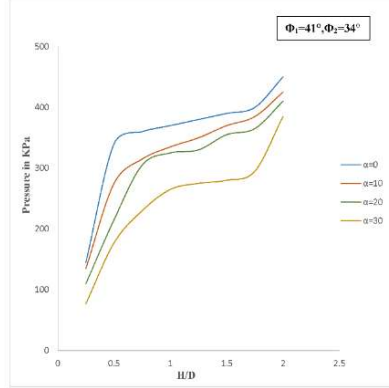

(e)

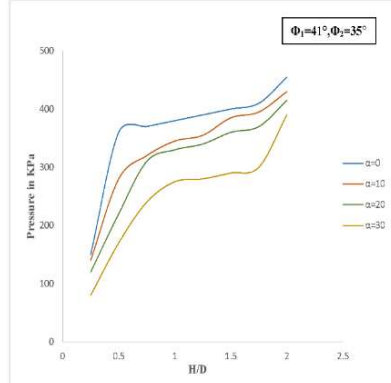

(g)

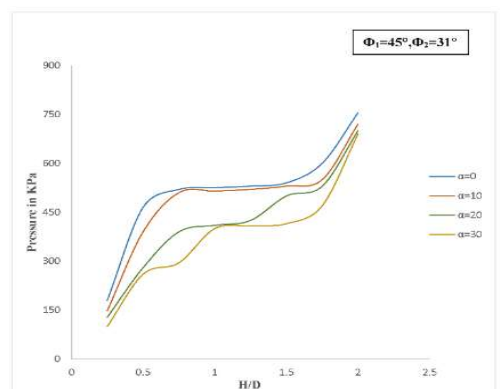

(b)

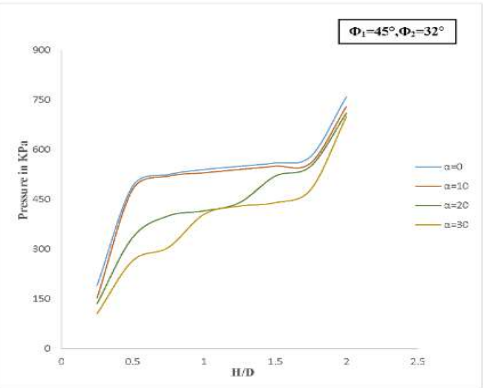

(d)

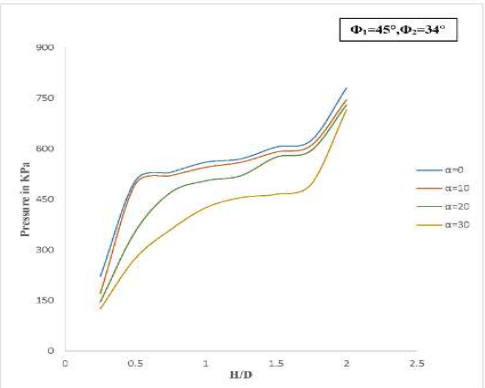

(f)

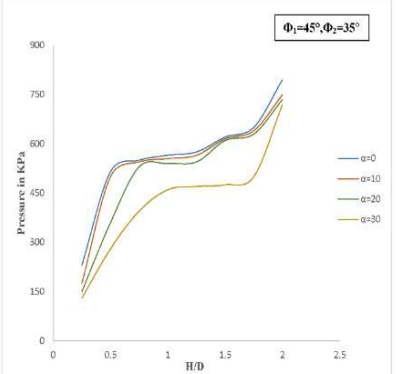

(h)

Fig. 7. Graph between Pressure Vs H/D (0.5-2.0) for $\alpha=0^{\circ}, 10^{\circ}, 20^{\circ}, 30^{\circ}$. (a) $\phi 1=41^{\circ}$, $\phi 2=31^{\circ}$. (b) $\phi 1=45^{\circ}, \phi 2=31^{\circ}$. (c) $\phi 1=41^{\circ}, \phi 2=32^{\circ}$. (d) $\phi 1=45^{\circ}, \phi 2=32^{\circ}$. (e) $\phi 1=41^{\circ}$, $\phi 2=34^{\circ}$. (f) $\phi 1=45^{\circ}, \phi 2=34^{\circ}$. (g) $\phi 1=41^{\circ}, \phi 2=35^{\circ}$. (h) $\phi 1=45^{\circ}, \phi 2=35^{\circ}$ 
Changes in the higher friction angle of the upper layer, $\phi_{1}$ and the lower layer, $\phi_{2}$ leads to an increase in the bearing pressure. Fig. 7 (h) illustrates how the value of $\phi_{1}=45^{\circ}$ and $\phi_{1}=35^{\circ}$ when the value of the bearing pressure is maximal compared to the other combination of friction angle for the two-layer model.

\subsection{Failure Pattern}

Fig. 8 shows the failure pattern in the layered sand media. These failure patterns are shown in the vectorial view of the displacement and it is important to access it in the actual displacement under such loading conditions. This vectorial result is required in order to verify the type of shear failure occurring in the model. Under given soil layer properties and vertical-inclined loading, it seems that punching shear failure occurs, which then starts deviating towards the upside as the lower layer starts. It seems that when a vertical load is applied, the vector deviates from the same angle in either direction, but as the inclination is increased along the vertical, the deviation of the vector increases along the direction of the loading. Similar results of the failure patterns are obtained for all combinations of the friction angle of the upper and lower layers as well as for the H/D ratios. The insights gained from the analysis above on the pattern of failure will be suitable for the development of analytical expression.

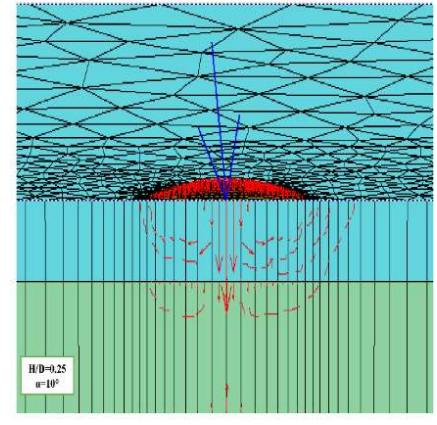

(a)

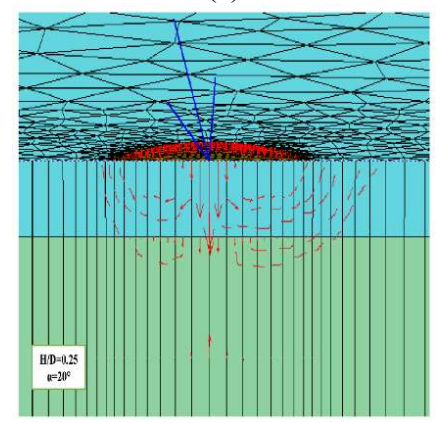

(c)

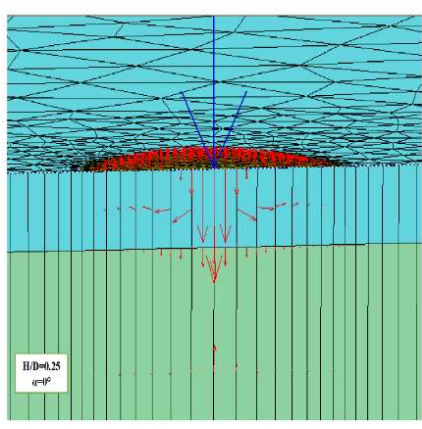

(b)

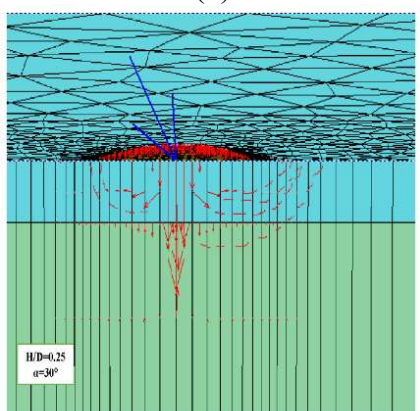

(d)

Fig. 8. Failure patterns of the soil layer in the vectorial view (a) $\alpha=0^{\circ}$, (b) $\alpha=10^{\circ}$, (c) $\alpha=20^{\circ}$, (d) $\alpha=30^{\circ}$ 
Table 3. Plaxis-3D model test data. (a), (b), (c)

(a)

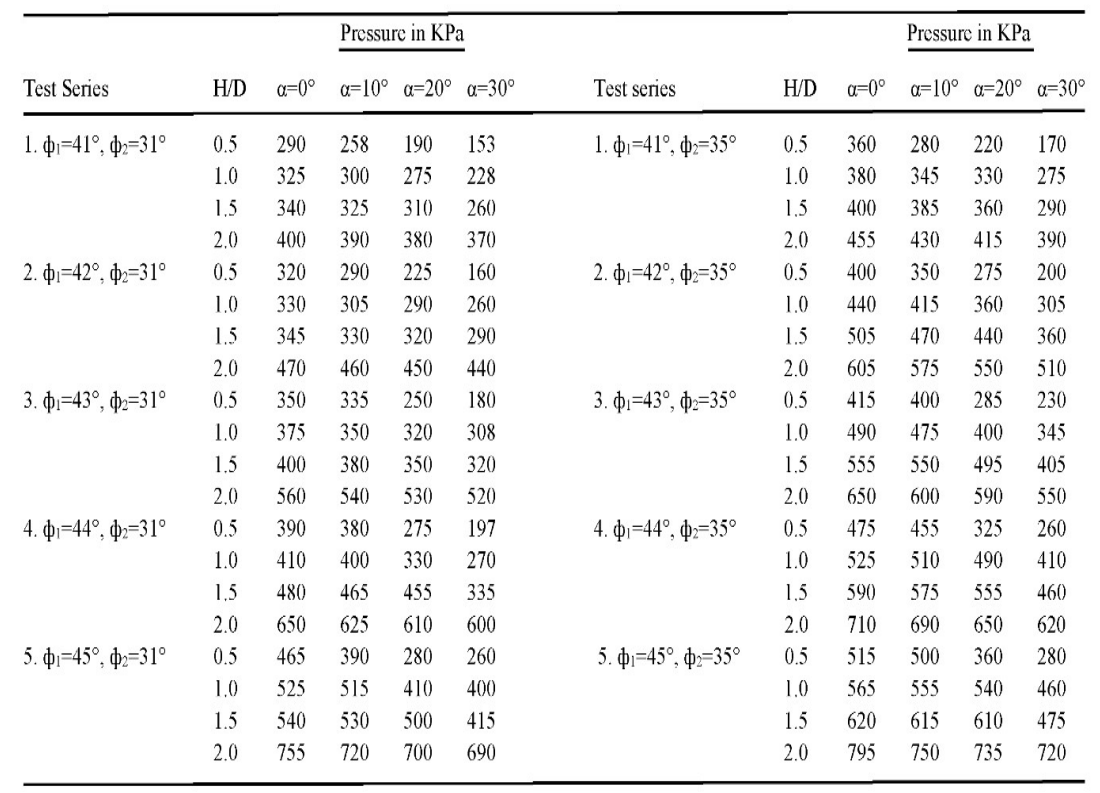

(b)

\begin{tabular}{|c|c|c|c|c|c|c|c|c|c|c|c|}
\hline \multirow[b]{2}{*}{ Test Scrics } & \multirow[b]{2}{*}{$\mathrm{H} / \mathrm{D}$} & \multicolumn{4}{|c|}{$\underline{\text { Pressure in } \mathrm{KPa}}$} & \multirow[b]{2}{*}{ Test serics } & \multirow[b]{2}{*}{$\mathrm{H} / \mathrm{D}$} & \multirow[b]{2}{*}{$\alpha=0^{\circ}$} & \multicolumn{2}{|c|}{ Pressure in $\mathrm{KPa}$} & \multirow[b]{2}{*}{$\alpha=30^{\circ}$} \\
\hline & & $\alpha=0^{\circ}$ & $\alpha=10^{\circ}$ & $\alpha=20^{\circ}$ & $\alpha=30^{\circ}$ & & & & $\alpha=10^{\circ}$ & $\alpha=20^{\circ}$ & \\
\hline \multirow[t]{4}{*}{ 1. $\phi_{1}=41^{\circ}, \phi_{2}=32^{\circ}$} & 0.5 & 310 & 262 & 200 & 160 & \multirow[t]{4}{*}{ 1. $\phi_{1}=41^{\circ}, \phi_{2}=33^{\circ}$} & 0.5 & 325 & 270 & 205 & 164 \\
\hline & 1.0 & 335 & 318 & 310 & 240 & & 1.0 & 360 & 325 & 315 & 255 \\
\hline & 1.5 & 360 & 355 & 340 & 265 & & 1.5 & 380 & 355 & 350 & 275 \\
\hline & 2.0 & 430 & 410 & 390 & 375 & & 2.0 & 440 & 415 & 400 & 380 \\
\hline \multirow[t]{4}{*}{ 2. $\phi_{1}=42^{\circ}, \phi_{2}=32^{\circ}$} & 0.5 & 340 & 300 & 240 & 165 & \multirow[t]{4}{*}{ 2. $\phi_{1}=42^{\circ}, \phi_{2}=33^{\circ}$} & 0.5 & 360 & 315 & 255 & 175 \\
\hline & 1.0 & 360 & 340 & 330 & 275 & & 1.0 & 390 & 360 & 340 & 285 \\
\hline & 1.5 & 375 & 360 & 355 & 295 & & 1.5 & 420 & 400 & 365 & 310 \\
\hline & 2.0 & 485 & 475 & 460 & 445 & & 2.0 & 520 & 500 & 475 & 460 \\
\hline \multirow[t]{4}{*}{ 3. $\phi_{1}=43^{\circ}, \phi_{2}=32^{\circ}$} & 0.5 & 365 & 340 & 270 & 195 & \multirow[t]{4}{*}{ 3. $\phi_{1}=43^{\circ}, \phi_{2}=33^{\circ}$} & 0.5 & 385 & 360 & 275 & 210 \\
\hline & 1.0 & 385 & 365 & 355 & 325 & & 1.0 & 430 & 400 & 380 & 330 \\
\hline & 1.5 & 405 & 385 & 380 & 335 & & 1.5 & 480 & 470 & 430 & 375 \\
\hline & 2.0 & 565 & 555 & 540 & 530 & & 2.0 & 600 & 575 & 560 & 540 \\
\hline \multirow{4}{*}{ 4. $\phi_{1}=44^{\circ}, \phi_{2}=32^{\circ}$} & 0.5 & 400 & 390 & 295 & 205 & \multirow{4}{*}{ 4. $\phi_{1}=44^{\circ}, \phi_{2}=33^{\circ}$} & 0.5 & 425 & 410 & 305 & 225 \\
\hline & 1.0 & 425 & 410 & 380 & 335 & & 1.0 & 475 & 450 & 430 & 350 \\
\hline & 1.5 & 490 & 470 & 460 & 380 & & 1.5 & 520 & 510 & 485 & 400 \\
\hline & 2.0 & 660 & 630 & 615 & 605 & & 2.0 & 680 & 655 & 620 & 610 \\
\hline \multirow[t]{4}{*}{ 5. $\phi_{1}=45^{\circ}, \phi_{2}=32^{\circ}$} & 0.5 & 490 & 480 & 335 & 265 & \multirow[t]{4}{*}{ 5. $\phi_{1}=45^{\circ}, \phi_{2}=33^{\circ}$} & 0.5 & 495 & 485 & 345 & 270 \\
\hline & 1.0 & 540 & 530 & 415 & 405 & & 1.0 & 550 & 535 & 470 & 410 \\
\hline & 1.5 & 560 & 550 & 520 & 440 & & 1.5 & 585 & 570 & 545 & 455 \\
\hline & 2.0 & 760 & 730 & 710 & 700 & & 2.0 & 770 & 735 & 720 & 705 \\
\hline
\end{tabular}


(c)

\begin{tabular}{llllll}
\hline & & \multicolumn{4}{c}{ Pressure in KPa } \\
Test Series & $H / D$ & $\alpha=0^{\circ}$ & $\alpha=10^{\circ}$ & $\alpha=20^{\circ}$ & $\alpha=30^{\circ}$ \\
\hline $1 . \Phi_{1}=41^{\circ}, \phi_{2}=34^{\circ}$ & 0.5 & 340 & 275 & 215 & 177 \\
& 1.0 & 370 & 335 & 325 & 265 \\
& 1.5 & 390 & 370 & 355 & 280 \\
& 2.0 & 450 & 425 & 410 & 385 \\
$2 . \Phi_{1}=42^{\circ}, \phi_{2}=34^{\circ}$ & 0.5 & 380 & 335 & 265 & 185 \\
& 1.0 & 420 & 390 & 350 & 295 \\
& 1.5 & 465 & 425 & 400 & 335 \\
& 2.0 & 585 & 545 & 510 & 480 \\
$3 . \Phi_{1}=43^{\circ}, \phi_{2}=34^{\circ}$ & 0.5 & 400 & 380 & 280 & 220 \\
& 1.0 & 460 & 435 & 390 & 340 \\
& 1.5 & 510 & 500 & 465 & 395 \\
$4 . \Phi_{1}=44^{\circ}, \phi_{2}=34^{\circ}$ & 2.0 & 625 & 590 & 575 & 545 \\
& 0.5 & 455 & 430 & 315 & 245 \\
& 1.0 & 500 & 475 & 460 & 380 \\
& 1.5 & 560 & 535 & 515 & 430 \\
$5 . \Phi_{1}=45^{\circ}, \phi_{2}=34^{\circ}$ & 2.0 & 695 & 670 & 635 & 615 \\
& 0.5 & 505 & 495 & 355 & 275 \\
& 1.0 & 560 & 545 & 505 & 425 \\
& 1.5 & 605 & 590 & 575 & 465 \\
& 2.0 & 780 & 745 & 730 & 715 \\
\hline & & & & &
\end{tabular}

\section{CONCLUSION}

The present numerical analysis study is based on the finite-element method model test using Plaxis-3D. The software is validated with the experimental data (Ornek et al., 2012) to check its accuracy. There is a slight difference in results between the experimental and FEM tests, being an $8 \%$ difference, due to the meshing done in the model. Furthermore, the layered granular soil media is modelled under different loading conditions, varied friction angles of the upper layer (dense layer) and lower layer (loose sand), and varied H/D ratios from 0.5-2.0. From section 4, the following conclusions are drawn:

- Different values of the thickness of the upper layer are considered, the bearing pressure increases as the thickness of the dense sand layer increases, Fig. 6.

- Bearing pressure decreases as the inclination increases with respect to the vertical table 3 .

- Increasing the friction angle $\phi_{1}$ of the dense sand layer increases bearing pressure, Fig. 6, table 3.

- Punching shear failure is observed in the layered sand media, Fig. 8. 
Acknowledgements The authors would like to thank the Central Building Research Institute (CSIR-CBRI), Roorkee for providing us with the opportunity to utilize Plaxis-3D.

Conflict of interest-The authors have no conflict of interest with anyone related to the material presented in the paper.

\section{REFERENCES}

1. Acharyya, R and Dey, A 2017. Finite Element Investigation of the Bearing Capacity of Square Footings Resting on Sloping Ground. INAE Letters, 2(3), 97-105.

2. Bolton, MD 1986. The strength and dilatancy of sands. Geotechnique, 36(1), 65-78.

3. Bowles, JE 1977. Foundation analysis and design. McGraw-Hill.

4. Burd, HJ and Frydman, S 1997. Bearing capacity of plane-strain footings on layered soils. Canadian Geotechnical Journal, 34(2), 241-253. https://doi.org/10.1139/cgj-34-2-241.

5. Chakraborty, D, Kumar, J 2015. Seismic bearing capacity of shallow embedded foundations on a sloping ground surface. International Journal of Geomechanics, 15(1), 1-8.

6. HANNA, AM 1981. Foundation on Strong Sand Overlying Weak Sand. $J$. Geotech. Engrg. Div., 107(7), 915-927.

7. HANNA, AM 1982. Bearing Capacity of Foundations on a Weak Sand Layer Overlying a Strong Deposit. Can Geotech J, V 19(N 3), 392-396.

8. Khatri, VN, Kumar, J and Akhtar, S 2017. Bearing capacity of foundations with inclusion of dense sand layer over loose sand strata. International Journal of Geomechanics, 17(10), 1-8.

9. Meyerhof, GG 1974. Ultimate Bearing Capacity of Footings on Sand Layer Overlying Clay. Can Geotech J, 11(2), 223-229.

10. Michalowski, RL and Shi, L 1995. Bearing capacity of footings over twolayer foundation soils. Journal of Geotechnical Engineering, 121(5), 421428.

11. Ornek, M, Demir, A, Yildiz, A and Laman, M 2012. Numerical analysis of circular footings on natural clay stabilized with a granular fill. Acta Geotechnica Slovenica, 9(1), 61-75.

12. Sharma, V and Kumar, A 2018. Behavior of ring footing resting on reinforced sand subjected to eccentric-inclined loading. Journal of Rock Mechanics and Geotechnical Engineering, 10(2), 347-357.

13. Shiau, JS, Lyamin, AV and Sloan, SW 2003. Bearing capacity of a sand layer on clay by finite element limit analysis. Canadian Geotechnical Journal, 40(5), 900-915. 
NUMERICAL STUDY OF THE BEHAVIOUR OF A CIRCULAR FOOTING ON A LAYERED GRANULAR SOIL UNDER VERTICAL AND INCLINED LOADING

14. Thakur, A and Dutta, RK 2020. Experimental and numerical studies of skirted hexagonal footings on three sands. SN Applied Sciences, 2(3), 1-11.

15. Zidan, AF 2012. Numerical Study of Behavior of Circular Footing on Geogrid-Reinforced Sand Under Static and Dynamic Loading. Geotechnical and Geological Engineering, 30(2), 499-510.

Editor received the manuscript: 20.10 .2020 